\title{
Evaluation of Road Infrastructure Alternatives Through a Saving Gradient in Travel Times. Case Study: Second Connection Villamaría- Manizales, Colombia
}

\author{
Diego A. Escobar ${ }^{1}$, Santiago Cardona ${ }^{1} \&$ Carlos A. Moncada ${ }^{2}$ \\ ${ }^{1}$ Universidad Nacional de Colombia, Sede Manizales. Facultad de Ingeniería y Arquitectura, Departamento de \\ Ingeniería Civil, Carrera 27 \# 64-60, Manizales, 170004, Colombia. Email: daescobarga@unal.edu.co; \\ scardonau@unal.edu.co \\ ${ }^{2}$ Universidad Nacional de Colombia, Sede Bogotá. Facultad de Ingeniería, Departamento de Ingeniería Civil y \\ Agrícola, Ciudad Universitaria, Edificio 214 oficina 417, Bogotá, 111321, Colombia. Email: \\ camoncadaa@unal.edu.co \\ Correspondence: Diego A. Escobar, Universidad Nacional de Colombia, Sede Manizales. Facultad de Ingeniería \\ y Arquitectura, Departamento de Ingeniería Civil, Carrera 27 \# 64-60, Manizales, 170004, Colombia. E-mail: \\ daescobarga@unal.edu.co
}

Received: July 12, 2018

Accepted: July 19, 2018

Online Published: July 28, 2018

doi:10.5539/mas.v12n8p103

URL: https://doi.org/10.5539/mas.v12n8p103

\begin{abstract}
In the last century, the migration of people from rural to urban areas of cities has generated a set of dynamics in different sectors such as social, economic, educational that have led cities to collaborate among them, generating a constant synergy in order to obtain a sustained development in multiple aspects. In this sense, Manizales as the capital of the department of Caldas in Colombia has generated a conurbation with the nearest neighboring municipality, Villamaría reaching a combined population of 419 943. Although this synergy has taken place for several decades, these municipalities only have a place of connection, because they are separated by a geographical barrier, the Chinchiná River. This connection has had clear connection problems, due to the high flow of vehicles that move between both municipalities, so it is essential to project a second connection, to further boost mobility among its inhabitants. For this reason, in this research four (4) alternatives of connection are proposed, according to the suggestions of the Manizales 2017 Mobility Master Plan, through the calculation of the global average accessibility and the quantification of the gradient of savings generated in the average times of trip, based on the current situation of both cities. The results show which is the alternative that benefits population the most in terms of travel time savings, although three of them generate considerable savings and only one is discarded because it benefits a smaller number of inhabitants in very low percentages of savings compared to the others. The evaluation of infrastructure alternatives through the gradient of savings in travel times is useful to determine the best options in the pre-feasibility phase of investment projects in the transport area.
\end{abstract}

Keywords: Alternative evaluation, case study, global mean accessibility, road infrastructure network, saving gradient, pre-feasibility

\section{Introduction}

In recent decades, cities around the world have chosen to use transport models to justify investments in the area of mobility such as new roads, bridges, connections and interchanges as well as the implementation of new public transport systems such as metro, cable, BRT or trams, because these demand a large monetary, fiscal, political and time investment, from its planning and construction to its implementation (Marvin \& Guy, 1999; Ortúzar \& Willumsen, 1994; Te Brömmelstroet \& Bertolini, 2011). In this sense, supply models such as accessibility seek to quantify the supply of transport and equipment in order to find a current scenario and thus make better decisions based on the greatest benefit for the population. On the other hand, the different governmental institutions have adopted different methodologies, seeking to organize their planning in the best way. In Colombia, through the law 338 of 1997, the elaboration of Territorial Planning Plans (POT) was regulated, in the field of urbanism, which functions as a tool for planning and ordering the territory, determining rules in various areas such as the uses of soil, environment, and construction, among others. These have different scopes, depending on the number of 
inhabitants of the city or municipality and have a validity of up to twelve (12) years (Congress of the Republic of Colombia, 1997). Also, through the law 1083 of 2006, the various actions that cities should follow in the field of urban mobility in search of sustainability in transport were determined, prioritizing alternative modes of transport such as bicycle and public transport, as well as the passage to cleaner technologies in vehicles such as electricity. Through the Urban Mobility Plans, which have a diagnosis of the current situation of the city and formulate actions and projects in the short, medium and long term in order to achieve the objectives of better urban mobility (Congress of the Republic from Colombia, 2006).

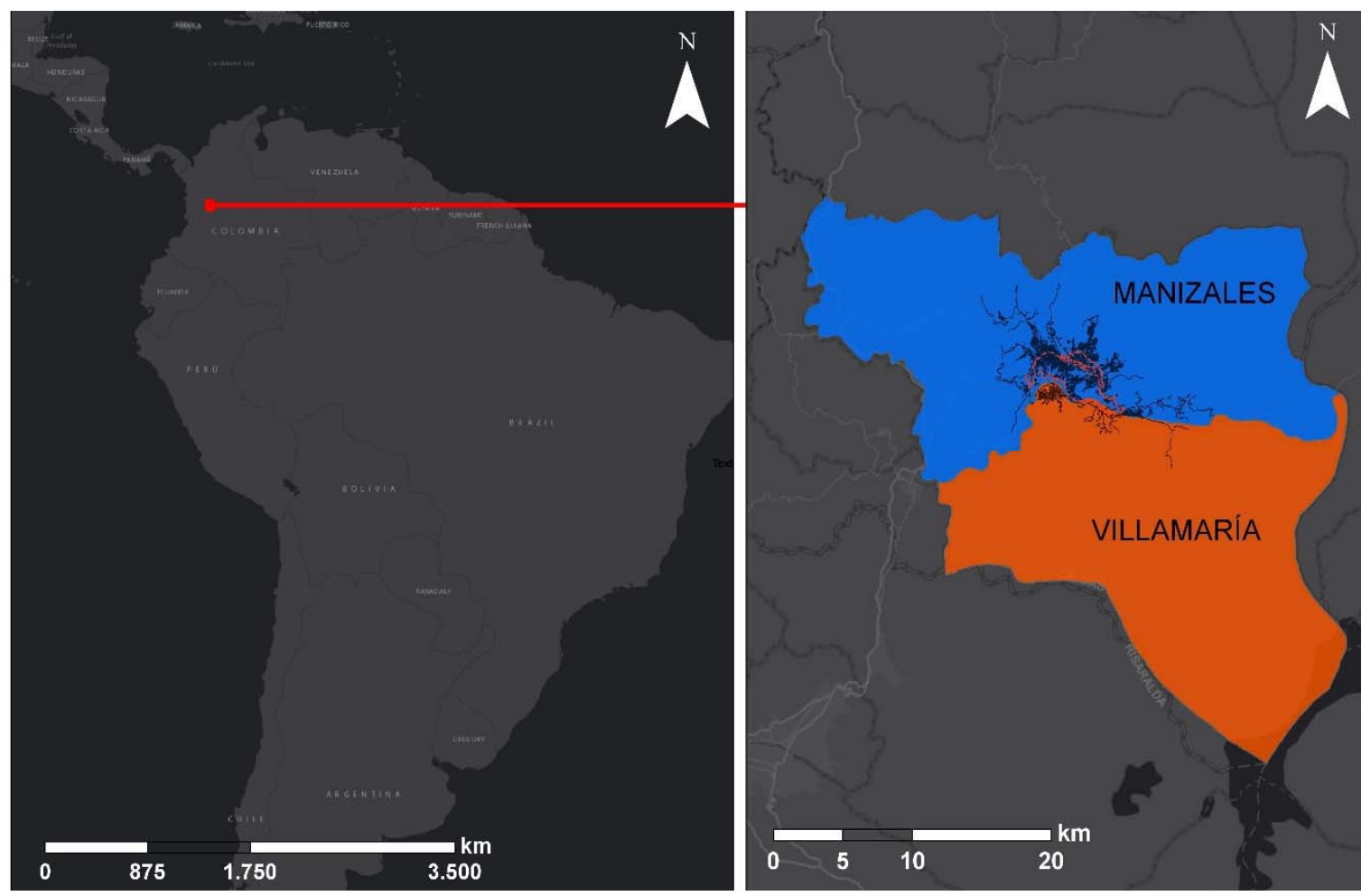

Figure 1. Study Zone Georrefernencing

With respect to this, Manizales, capital of the department of Caldas in Colombia (Blue in figure 1) developed, formulated and approved the Land Management Plan 2017 - 2031 (Mayoralty Manizales, 2017a) and the Mobility Master Plan 2017 - 2032 -MMP (Mayoralty of Manizales, 2017c, 2017b). According to the latter, Manizales travels (982 231 daily trips) has a large percentage of people who walk (29\%) and public transport (24\%), which has flexible offers such as the bus, small buses, aerial tramway and collective mini buses, although the latter has seen its demand decreased in alarming numbers throughout the country (Cardona, Escobar, \& Moncada, 2017), moving to the private vehicle $(25 \%)$ whose motorization rate of cars and motorcycles has been increasing, what will make the road network unsustainable in the coming decades (Manizales Como Vamos, 2017) multiplying the importance of actions such as those proposed in the PPM through the 138 projects developed along 6 pillars such as the empowerment of free space for pedestrian transit, the use of bicycles and the development of the Strategic Public Transport System- SETP, among others. Among these projects, the various proposals made in the formulation of the MMP for a second road access to the municipality of Villamaría (Orange in Figure 1), since it is the only connection that is currently enabled, has constant congestion problems, that produce an increase in travel times affecting the multiple trips that for different reasons are made between the two municipalities that together form a conurbation of approximately 419000 inhabitants for 2017 (DANE, 2010), which operates jointly (Mayoralty of Manizales , 2017b). The MMP proposes three tentative points for the new connection (see figure 2) although these are not evaluated by any known methodology, so in this investigation an evaluation of the second access to Villamaría will be made in the three proposed points (Two alternatives in the West and one in the North and one in the East in the municipality of Villamaría) through models of global average accessibility, which are transport supply models, which measure the benefit generated by new infrastructure works in the road network in terms of savings in the average travel time of the inhabitants (Moncada, Cardona, \& Escobar, 2018). 


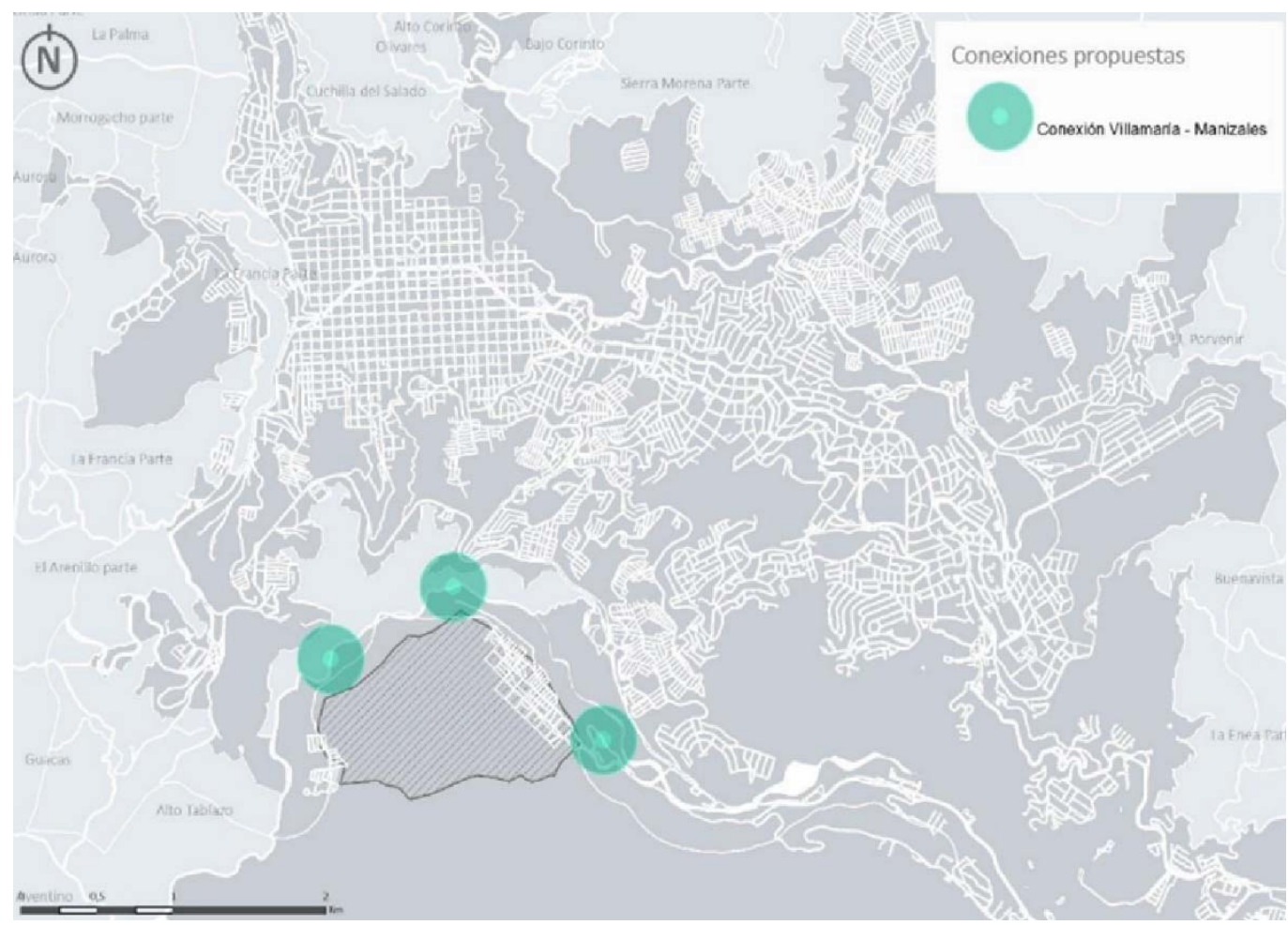

Figure 2. Alternative location for second conection Villamaria-Manizales (Mayoralty of Manizales, 2018b)

The global average accessibility is a model of transport offer that measures the connection between all the nodes of the road network by analyzing the minimum routes among them, obtaining the travel time matrix (Escobar \& García, 2012). This concept has evolved, since Hansen (1959) defined it as "... the potential opportunities for interaction ...", deriving in multiple approaches (Ingram, 1971) and types of measurement (Pirie, 1979). In addition, over the years, various researchers have made revisions of this concept (Dalvi \& Martin, 1976; Geurs \& Ritseman Van Eck, 2001; Geurs \& van Wee, 2004; Koenig, 1980; Morris, Dumble, \& Wigan, 1979), also defining the future focus and the different challenges it confronts in the field of research and urban planning (Geurs, De Montis, \& Reggiani, 2015; van Wee, 2016). On the other hand, it was Weibull who in 1976 defined accessibility as the physical proximity between two geographical points and proposed the main axioms that must be met to make an accurate calculation of the measure, supplemented by Miller (1999) years later. Furthermore, global average accessibility is a measure based on infrastructure, according to the perspectives adopted by Geurs and Ritsema van Eck (2001), since it uses the road infrastructure network and its average speeds as a fundamental input for the calculation (Moncada et al., 2018). In Manizales and the central region of Colombia, this type of measure has been used for similar investigations in the field of road infrastructure (Perilla, Cardona, \& Escobar, 2018) and prioritization of road projects (Escobar \& García, 2012), analysis of metropolitan areas (Escobar, Cardona, \& Moncada, 2018a), recovery charging (Escobar, Cardona, \& Moncada, 2018b), road concession analysis (MuñozEspinosa, 2016), among others.

Next, the research methodology applied in this article will be described and then the main results will be listed together with their respective discussion to finally frame the obtained conclusions.

\section{Methodology}

Figure 3 shows the flow diagram of the methodology applied in research. In the following items, each of the stages is described in detail.

\subsection{Validation of the Road Infrastructure Network and Construction of the Different Study Scenarios}

In the first instance, the validation of the road infrastructure network is made in the current situation. This must comply with the theory of graphs, which has been used in multiple applications in the area of transport, primarily for the representation of road infrastructure networks (Derrible \& Kennedy, 2009, Duarte, Becerra, \& Niño, 2008). This theory considers that a graph $(\mathrm{G})$ is composed of vertices (V) (called nodes in transport networks) and edges (E) (arcs in transport networks), where each edge is formed by a pair of vertices (Deo, 1974). This network was 
built for the construction of the PPMM of 2011 using tools of Geographic Information Systems (GIS) and has been constantly updated for more recent research (Escobar, Montoya, \& Moncada, 2018; Moncada et al., 2018; Montoya \& Escobar, 2017; Perilla et al., 2018).

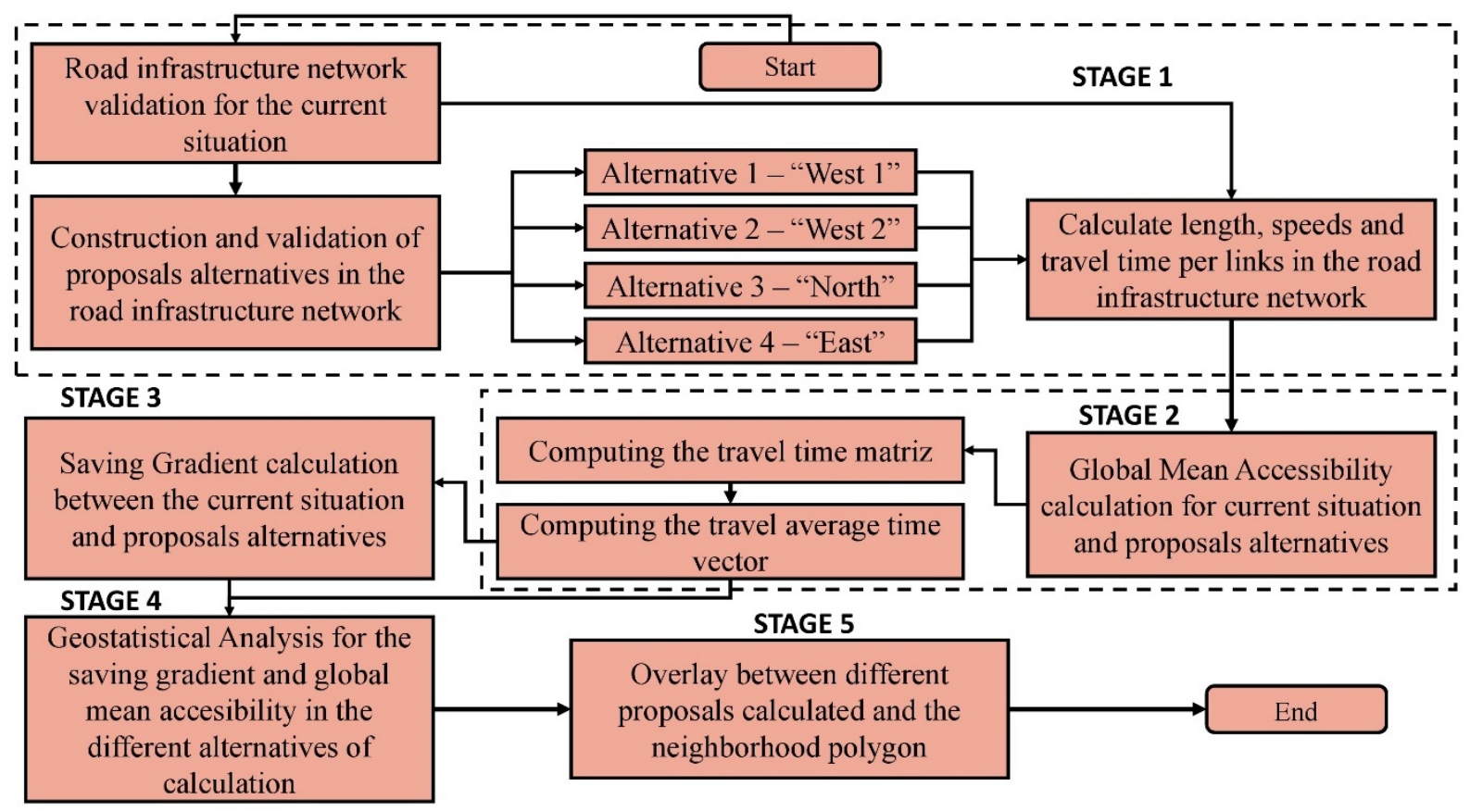

Figure 3. Investigation methodology

In the second instance, the construction of four (4) proposed scenarios for the second connection between Villamaría and Manizales takes place, taking into account the places marked by the MMP of 2017 (see figure 2).

Finally, in the current scenario and each proposed scenario, the travel times (tvi) must be calculated for each arc, taking into account the length (li) of each arc obtained by means of GIS tools and the speed (Vi), which It was computed thanks to global positioning systems (GPS), placed in different vehicles that crossed the road infrastructure network (Escobar \& García, 2012). For the proposed new routes, an average speed of $45 \mathrm{~km} / \mathrm{h}$ is defined for all the arcs.

\subsection{Calculation of Global Average Accessibility, Current Situation and Proposed Scenarios}

For each of the proposed scenarios (4) as well as for the current situation, the global average accessibility is calculated. For this, the TRANSCAD 7.0 software is used, which is a GIS software that has specialized complements in the transport field. First, the travel time matrix must be calculated between all the nodes that make up the road infrastructure network. This calculation is made using the Dijkstra algorithm of minimum roads (Dijkstra, 1959; Sanders \& Schultes, 2007), which optimizes the travel time between the different nodes taking into account the global penalty for the road infrastructure network, calculated by an empirical method in 0.58 minutes on the left and 0.49 minutes on the right. After obtaining the travel time matrix for each scenario, we proceed to calculate the average travel time vector $(\overline{T v l})$, by means of equation (1), which takes into account the sum of travel time between the origin (i) and destination (j) node pairs and the total number of nodes to which the network can travel (n-1) (Escobar et al., 2018a, Moncada et al., 2018). Also, this vector of average travel times must be related to the geographical coordinates of each node in order to perform the statistical analysis in later stages.

$$
T v_{U}=\frac{\sum_{f=1}^{n} t v_{t i}}{n-1}
$$

\subsection{Saving Gradient Vector Calculation}

In this instance of the investigation, the calculation of the saving gradient vector $\left(V_{s g}\left(\%_{0}\right)\right)$ is performed, 
comparing the current global average accessibility situation with the four (4) proposed second connection scenarios between Villamaria and Manizales. For this, the equation 2 is used, where $\overline{T^{2} v_{\rho g}}$ corresponds to the average travel time vector of the current situation and $T v_{\mathrm{p}}$ corresponds to the average travel time vector of the proposed scenarios (Moncada et al., 2018; Perilla et al., 2018). In this case, four savings gradient vectors are calculated, corresponding to the percentage saved at travel times with respect to the current situation generated by the new connection alternatives between Villamaría and Manizales.

$$
V_{s g}(\%)=\left(\frac{\overline{T v_{\sigma g}}-\overline{T v_{p g s}}}{T v_{\alpha s}}\right) * 100 \quad t=1,2,3,4 .
$$

\subsection{Construction of Isochrones Curves of Global Average Accessibility and Savings Gradient}

For the construction of the isochrones curves of global average accessibility and gradient savings, for the current situation and the different analyzed scenarios, the ordinary Kriging geo-statistical model is used, with a linear semi-variogram as a structural equation (Díaz Viera, 2002; Oliver \& Webster, 1990), which has been used in various investigations on issues related to transport (Escobar et al., 2018a, Lindner, Pitombo, Rocha, \& Quintanilha, 2016; Zhang \& Wang, 2014). In this case, the average time travel vectors are used as interpolation input, in the case of the global average accessibility and the savings gradient vectors, in the case of the savings gradient.

\subsection{Analysis of the Covered Population}

Finally, an analysis of population coverage is made by means of the isochrones curves of global average accessibility and savings gradient along with the neighborhood polygon of the city of Manizales and Villamaría (Moncada et al., 2018), which has information regarding the population living in each of the neighborhoods and their average socioeconomic stratum, which is a differential housing measure between 1 (low) and 6 (high), where the urban characteristic, and socio-economic variables are taken into account (Perilla et al., 2018). This will allow us to obtain the ogive percentage of population covered in the case of the global average accessibility and the "Elbow" graph of savings coverage in the case of the savings gradient (Moncada et al., 2018, Perilla et al., 2018).

\section{Results and Discussion}

\subsection{Infrastructure Road Network, Current Situation and Proposed Scenarios}

In the upper left of figure 4 we can see the road infrastructure network of the city of Manizales and Villamaría, which has about $682 \mathrm{~km}$ of roads dedicated to vehicles. In the current situation, the connection between Villamaría and Manizales has a double lane road that is incorporated by means of a tunnel to the Pan-American highway, a few hundred meters from the transport terminal of the city, this connection, being unique, has high traffic congestion which will cause a collapse in mobility between these two conurbations in the coming years (Mayoralty of Manizales, 2017b). As for the alternatives for the second connection, the MMP pointed to three different places (see figure 2) of possible location. Therefore, in this study four connection alternatives are evaluated: two located in the western zone, one in the northern zone and one in the eastern zone. First, in the lower right corner we see the first alternative located in the west of Villamaría, which goes through "La Pradera" neighborhood and connects in Manizales near the National Men's Prison on the Pan-American Highway. Secondly, in the upper left there is the second alternative located in the west of Villamaría, which, like the previous alternative, goes through "La Pradera" of Villamaría neighborhood and connects with the city of Manizales on the Pan-American Highway on "La Uribe" sector. Third, in the central part of the left there is an alternative connection located in the northern part of Villamaría that connects near "La Fuente" intersection, located on the Pan-American highway. Finally, in the eastern part of Villamaría the alternative that connects near the transport terminal is observed, so it is located close to the current connection that Manizales and Villamaría have.

\subsection{Global Average Accessibility, Current Situation and Proposed Alternatives}

The isochrones curves of global average accessibility can be seen in Figure 5 where minimum times of 16.59 minutes and maximums of 52.11 minutes are recorded. In the central part of the city, good coverage is observed, with average travel times of less than 25 minutes, which indicates the good accessibility of its inhabitants through the road infrastructure network. On the other hand, in the peripheral parts of the city, times greater than 40 minutes are recorded, reaching 52.11 minutes in the northwestern part of the city. Figure 6 shows the analysis made between 
the isochronous curves and the population coverage. For the current situation, 32\% (134 353 inhabitants) of the population obtained average travel times of less than 20 minutes. 84\% (343 285 inhabitants) of the population is covered by average times of up to 25 minutes, which indicates a very favorable current scenario in terms of global average accessibility in the studied area. Figure 7 shows the result of the isochrones curves of global average accessibility for the different studied alternatives.

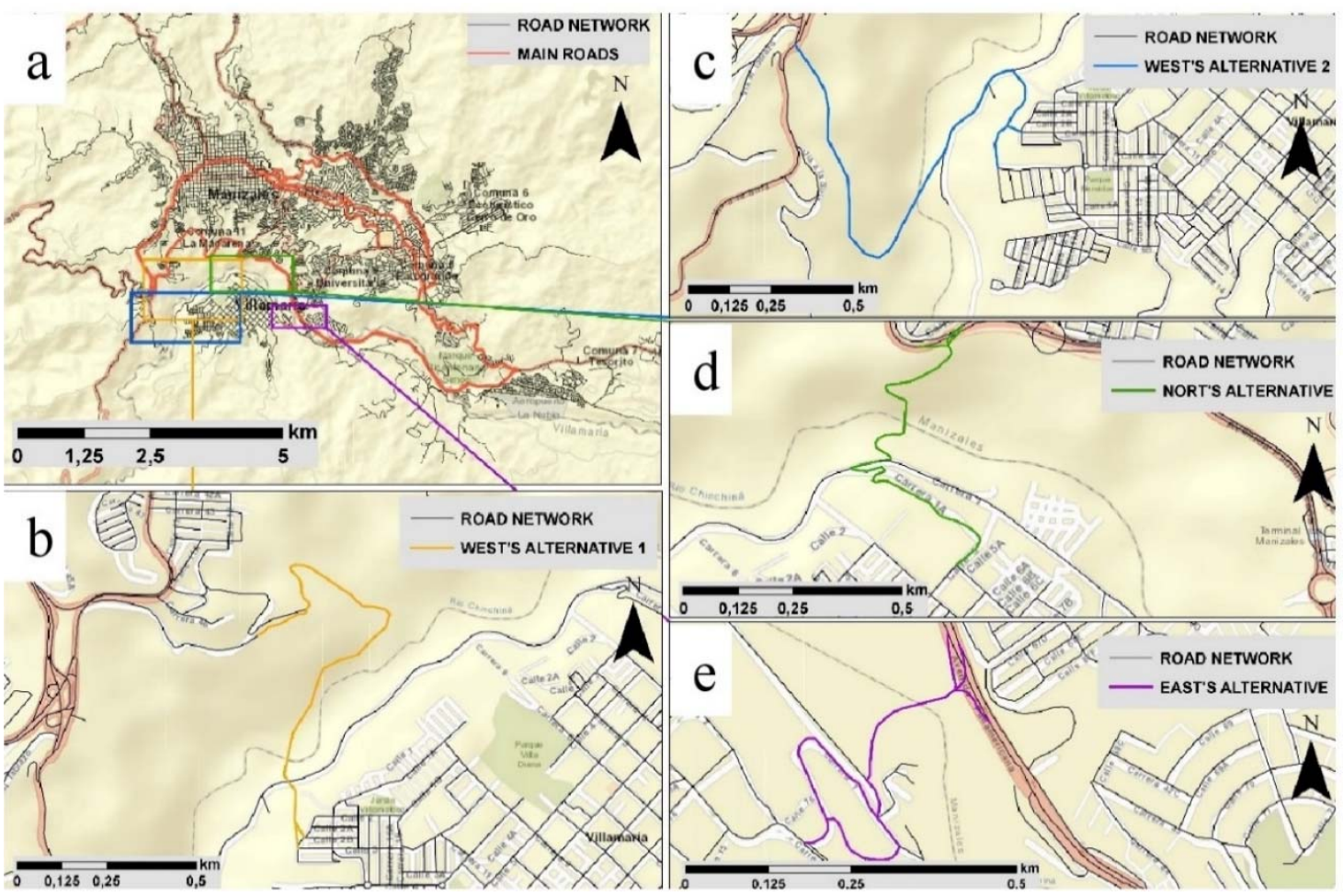

Figure 4. Road Network, a) Current situation. b) West's alternative-1. c) West's alternative-2. d) North's alternative and e) East's alternative

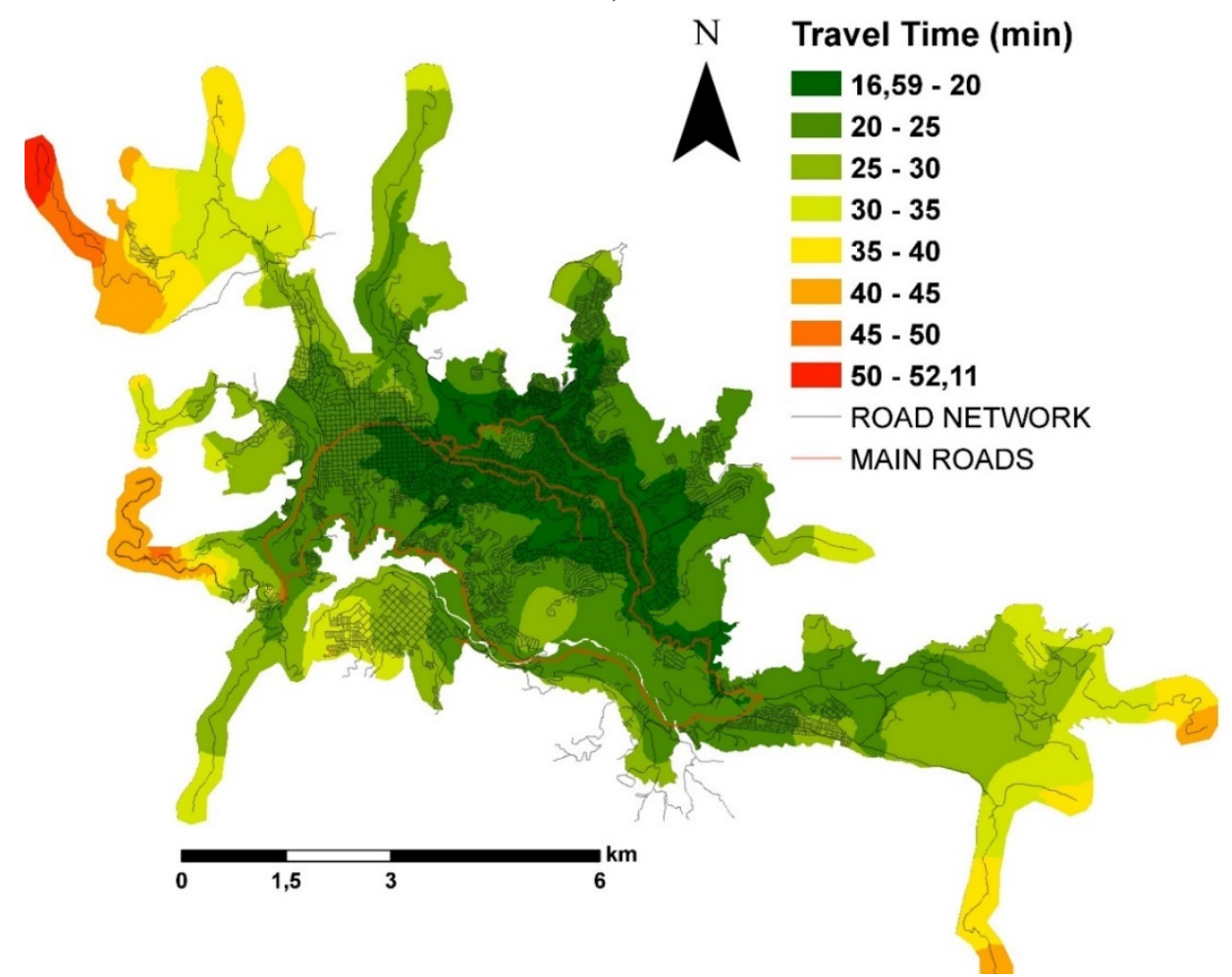

Figure 5. Global mean accessibility, current situation. 


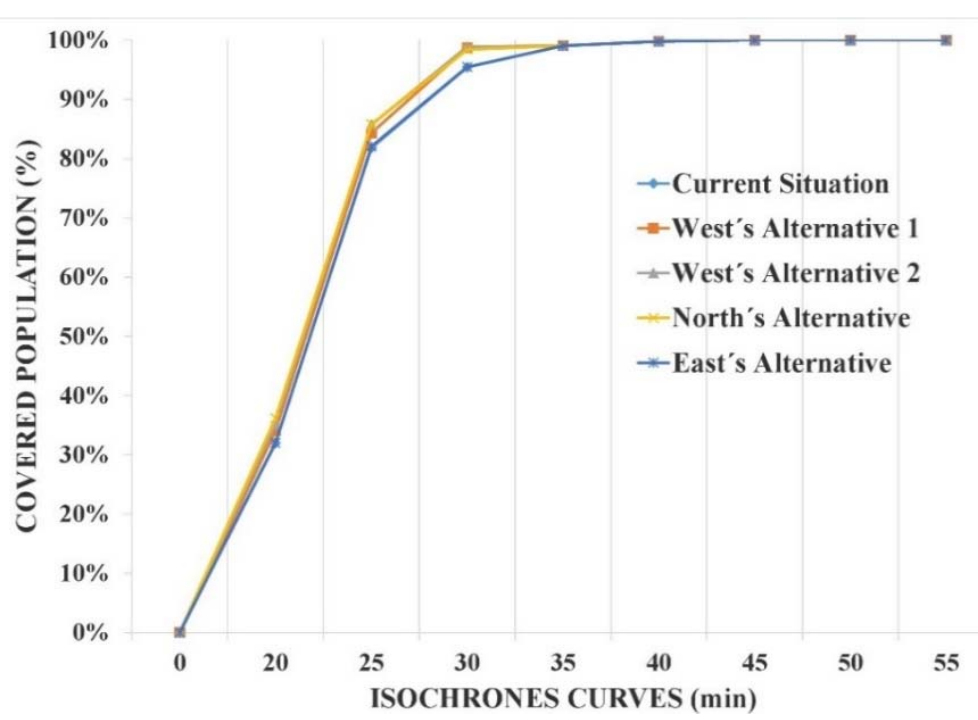

Figure 6. Covered population comparison with isochrones curves.
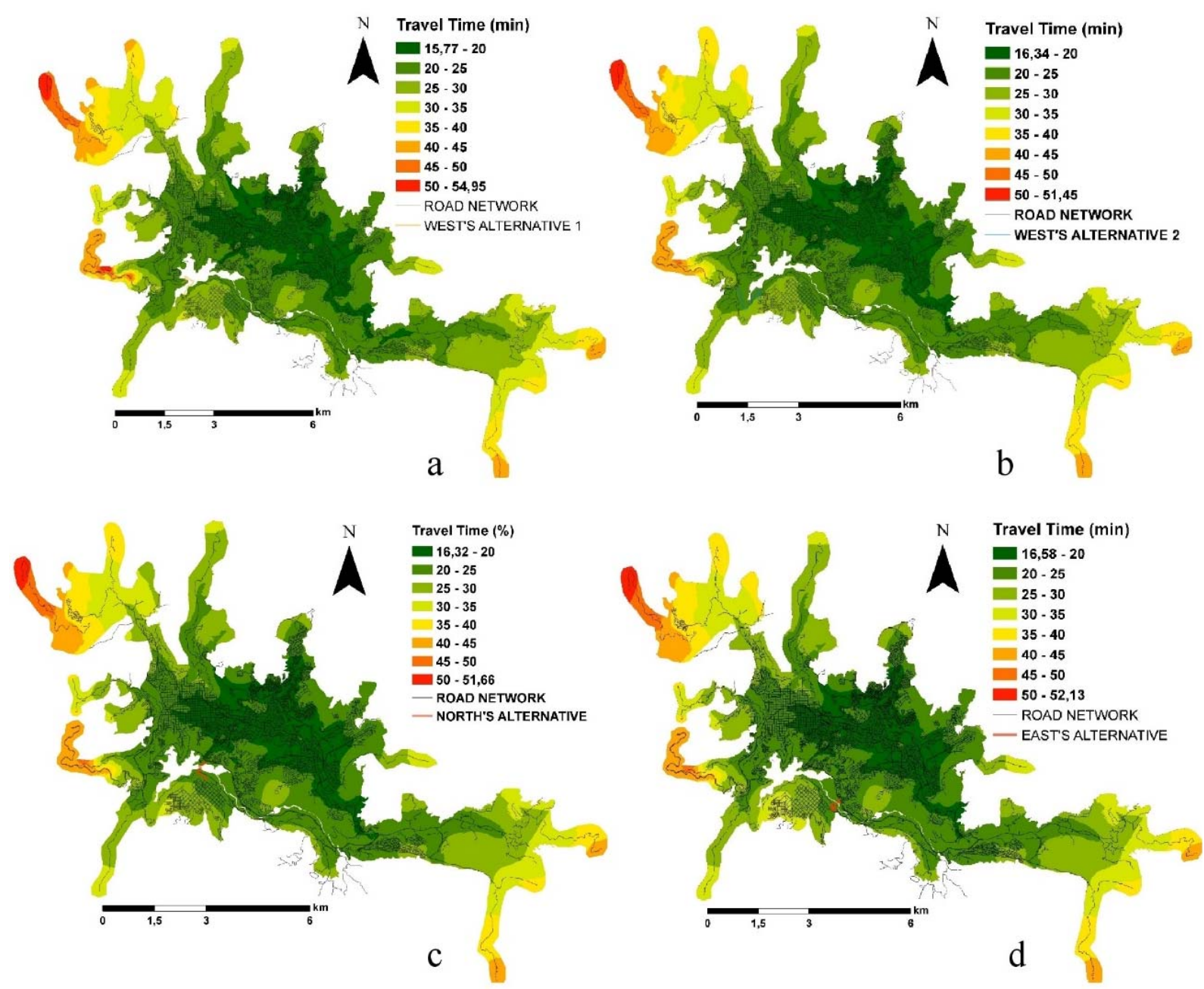

Figure 7. Global mean accessibility. a) West's alternative-1. b) West's alternative-2. c) North's alternative and d) East's alternative

Among the most relevant results is that the western-1 alternative decreased the average minimum travel time by 0.82 minutes, while the other alternatives decreased it by approximately 0.20 minutes, and even the eastern 
alternative did not represent significant changes since it only decreased the minimum time in 0.01 minutes. On the other hand, the analysis of population coverage, shown in Figure 6, indicates that the alternative West-2 and North increased by 4\% (16 787 inhabitants) population coverage for average travel times of less than 25 minutes, while the western alternative-1 increased this percentage by $2 \%$ (8 394 inhabitants) and the eastern alternative did not generate an increase in coverage.

\subsection{Savings Gradient, Current Situation vs Proposed Alternatives}

Figure 8 shows the isochronous gradient savings generated by the different alternatives proposed with respect to the current situation. In these, there are savings of up to $30 \%$ in the average travel times generated by alternative West-2. Likewise, the western- 1 and north alternative generate savings of up to $22.5 \%$ in the average travel times while the eastern alternative only achieves savings of up to $7.5 \%$, making it the least efficient alternative studied. On the other hand, although the alternative West-2 is the one that generates higher savings, it does not produce savings in the whole city, as the North alternative does, which generates a saving of at least $2.5 \%$ in the entire city.

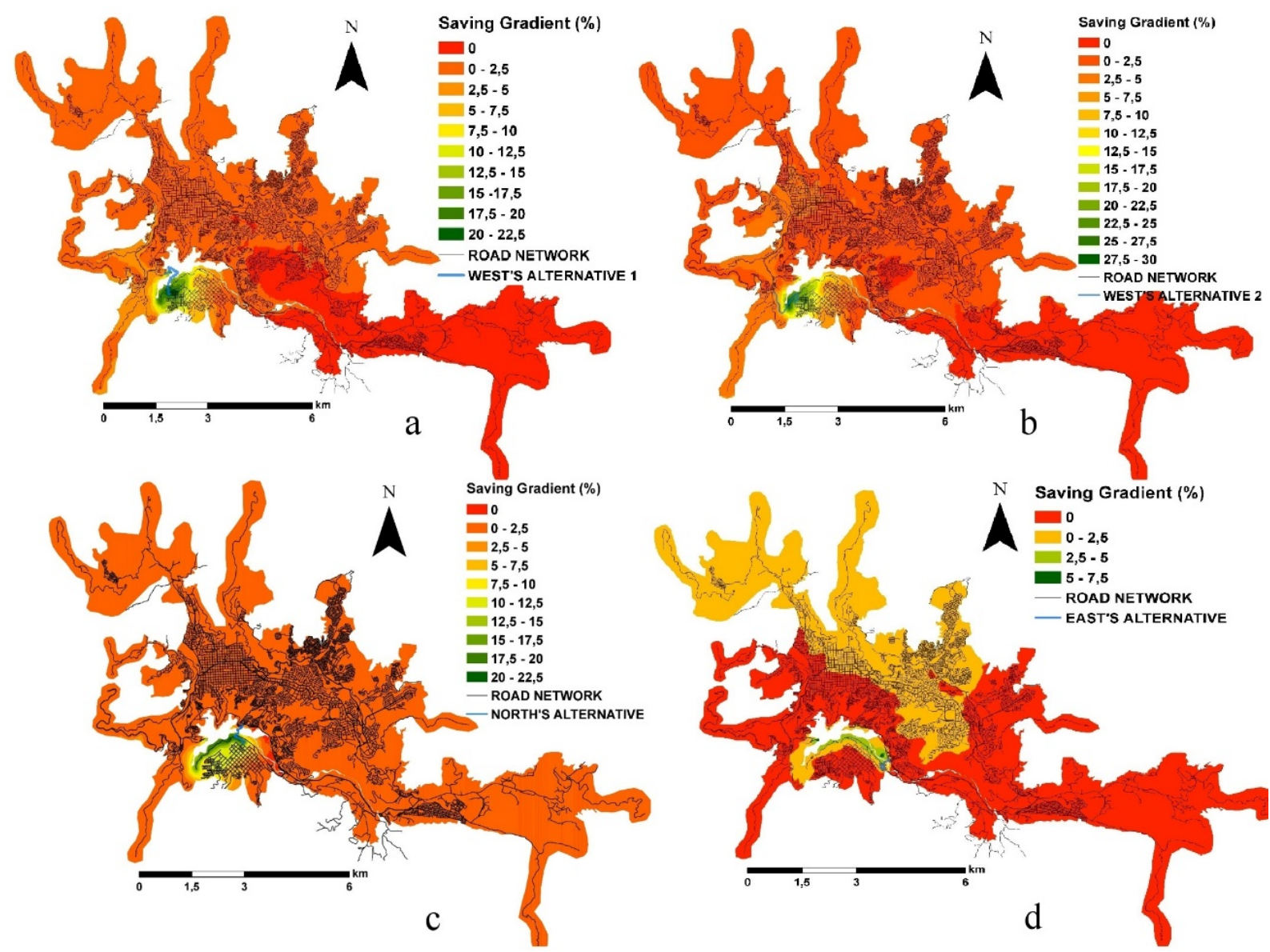

Figure 8. Saving Gradient, a) West's alternative-1. b) West's alternative-2. c) North's alternative and d) East's alternative

The population coverage analysis for the isochronous gradient savings curves (figure 9) indicates that the northern alternative generates savings of up to $2.5 \%$ for the entire population followed by the western 1 , western 2 and east alternative that reach coverage of $86 \%, 73 \%$ and $46 \%$ of the population respectively. If we continue to save up to $5 \%$, the most convenient alternative is the West 2 with 13\% (53 691 inhabitants), while the West 1 alternative reaches 10\% (42 011 inhabitants) and the North alternative 9\% (39 447 inhabitants). In this case, the eastern alternative already shows its infeasibility because it generates savings of up to $5 \%$ for only $1 \%$ of the population, which compared with the other alternatives is extremely unfavorable. It should be noted that the different alternatives, except for the eastern alternative, continue to generate savings in some percentage of the population, reaching a maximum, previously mentioned. Figures 10 to 13 show the analysis of population coverage, according to the socioeconomic stratum of each of the analyzed alternatives. This indicates that the population of stratum 3 (medium-low) obtains a higher percentage of savings, in all the proposed alternatives, except in the eastern 
alternative (see figure 13), in which the coverage of the savings generated is lower compared with the other strata. In addition, it should be noted that the stratum 1 (low), has significant savings in the different alternatives, which indicates that connectivity is improved to a percentage of inhabitants who have disadvantages at a social and economic level.

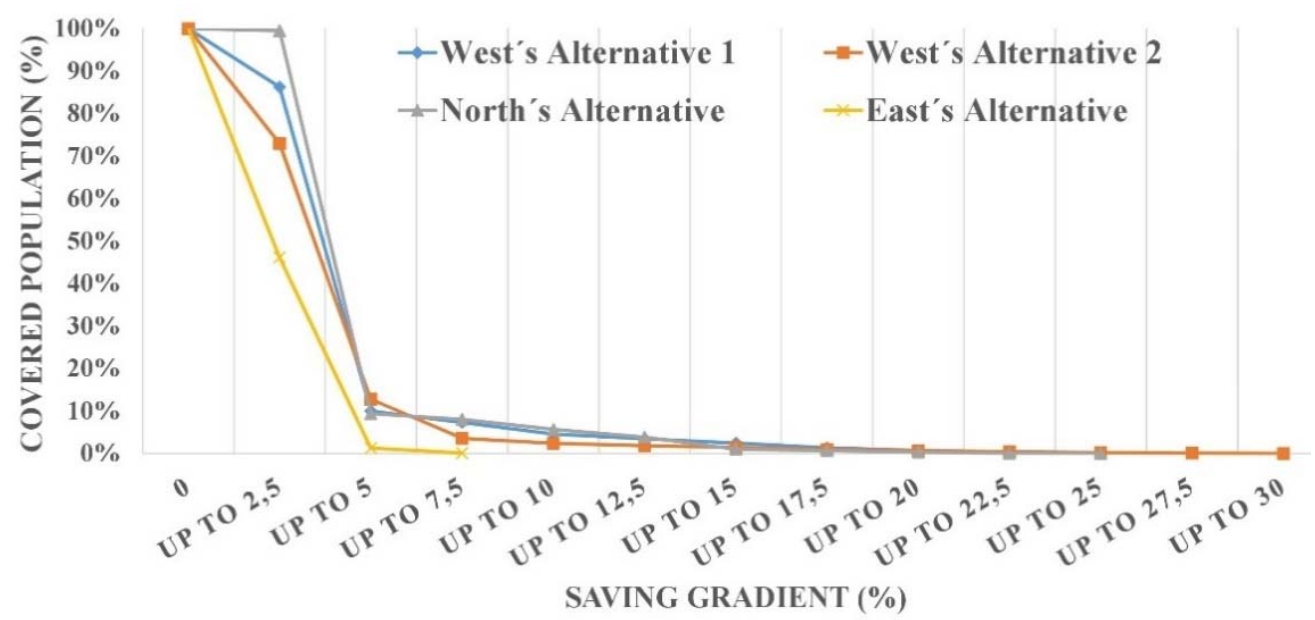

Figure 9. Covered population and saving gradient (\%)

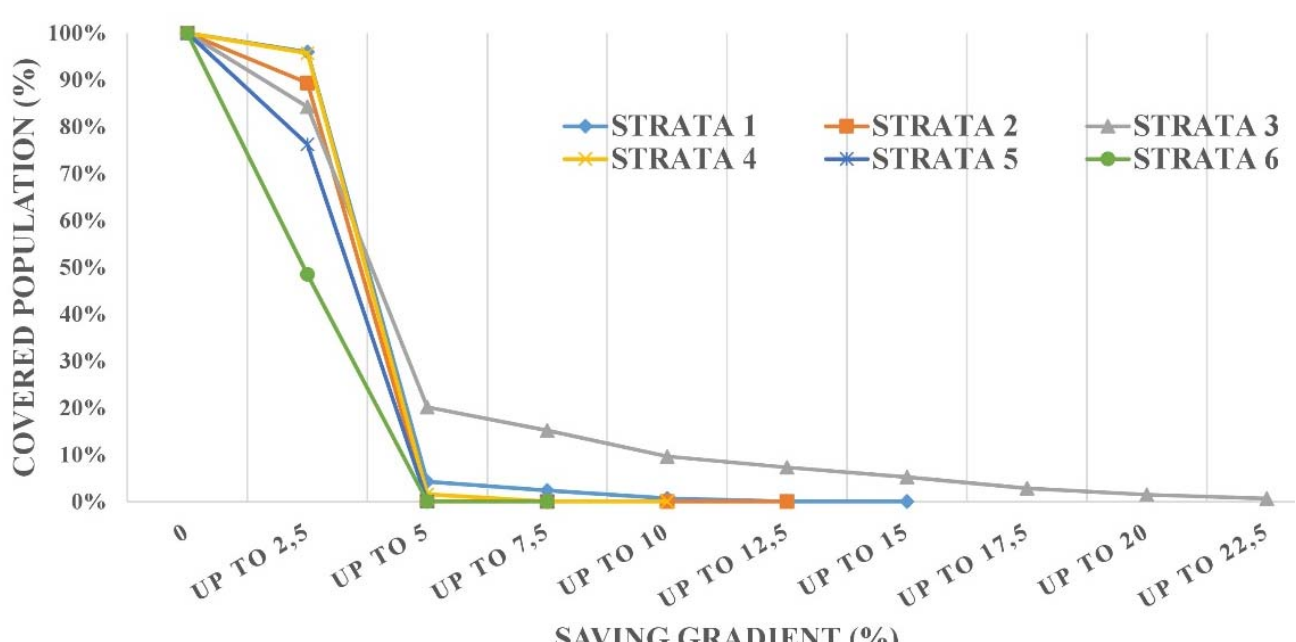

Figure 10. Covered population and saving gradient (\%), strata analysis in west's alternative-1

\section{Conclussions}

From the alternatives proposed as second access to Villamaría, all generated savings in the average travel times, however the eastern alternative, being close to the access that is in operation generates very low savings, making it unviable in the first instance. On the other hand, the western alternative- 2 being at the entrance of Manizales and connected with the neighborhood "La Pradera" in Villamaria, which has a high average travel time in the current situation, generates savings in average travel times of up to $30 \%$, being the one that generates the highest savings. Also, the alternatives West-1 and north generate up to $22.5 \%$ savings, however, although the alternative West-1 has the same output from Villamaría as the alternative West-2, it has a connection in Manizales that does not favor it as alternative West-2. As for the north alternative, it has a connection in Villamaría on the central part of the municipality, which helps savings to be distributed in a better way, as well as its connection with Manizales, making savings of at least $2.5 \%$ in all the area of study, something that is only achieved with this alternative. 


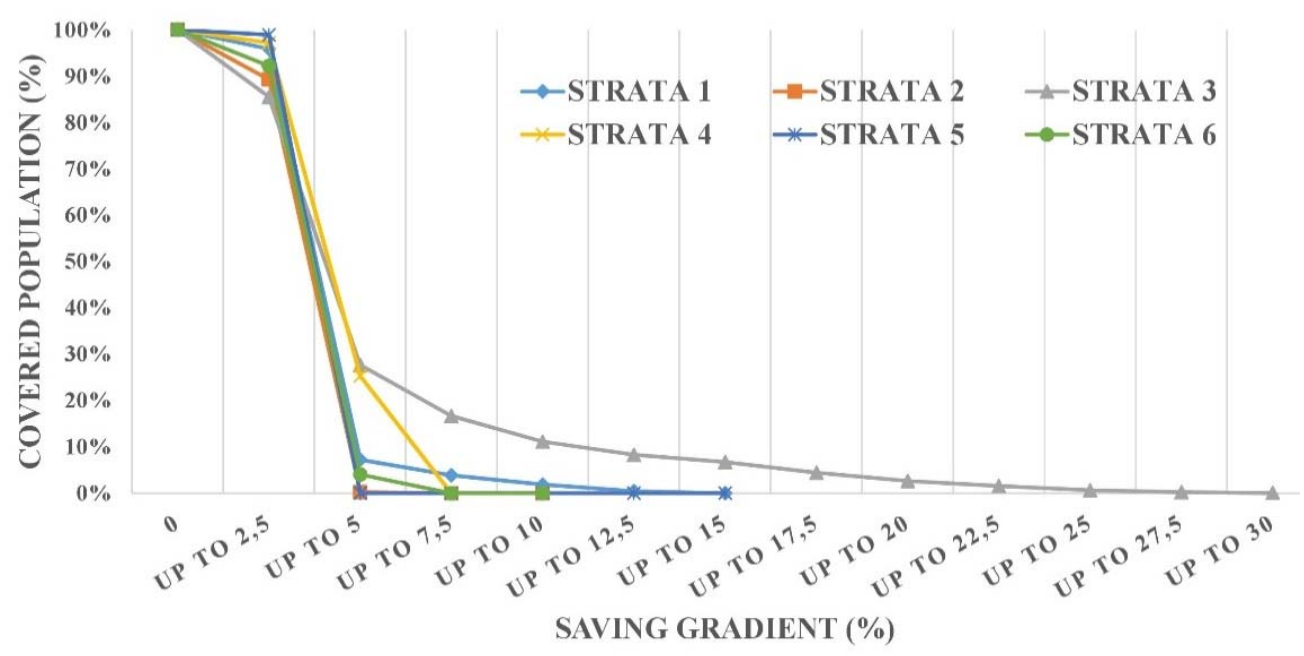

Figure 11. Covered population and saving gradient (\%), strata analysis in west's alternative-2

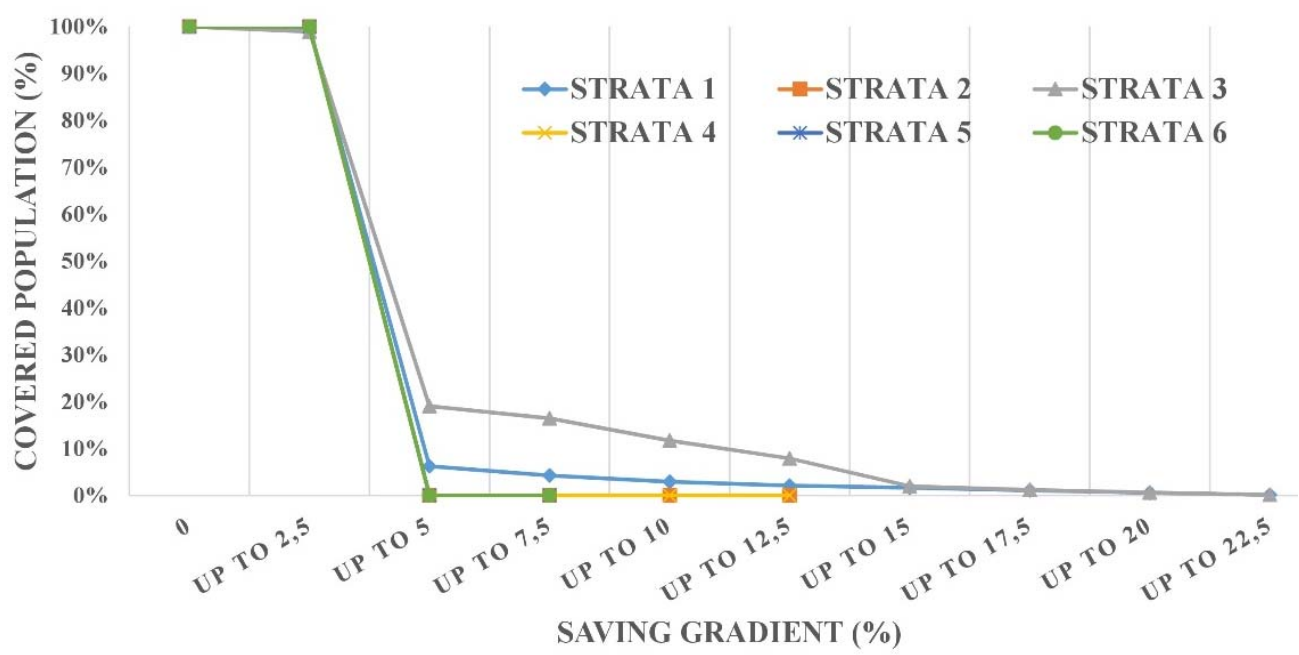

Figure 12. Covered population and saving gradient (\%), strata analysis in north's alternative

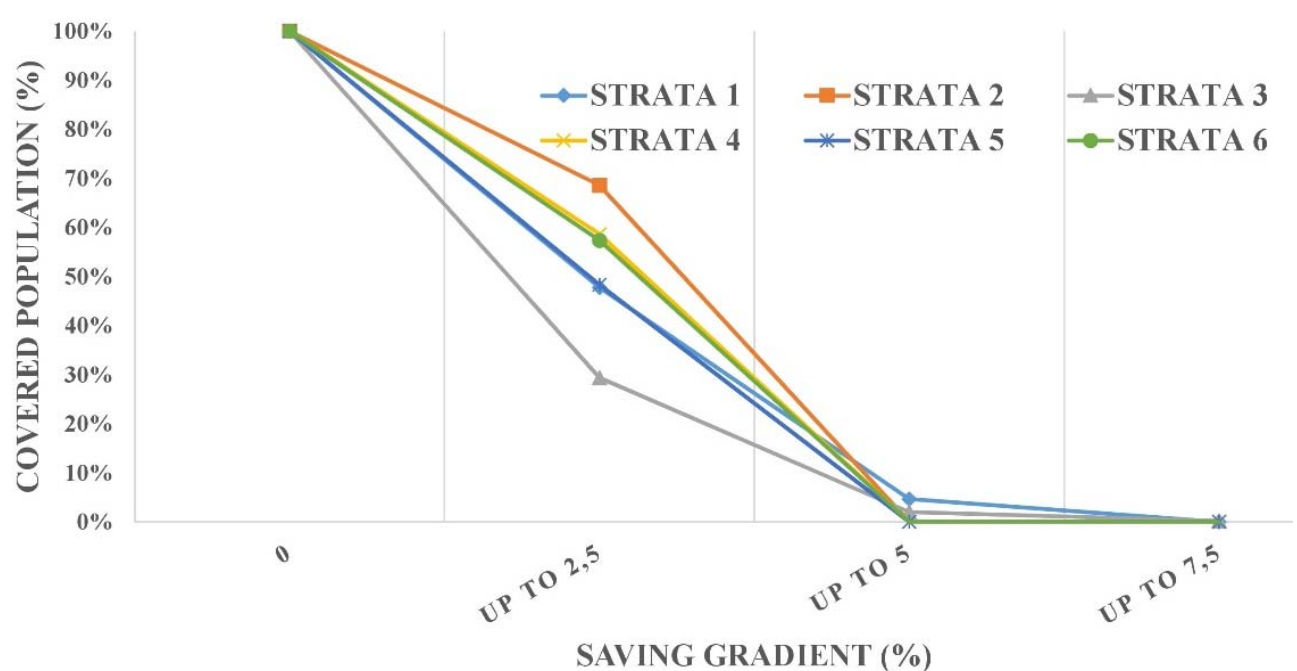

Figure 13. Covered population and saving gradient (\%), strata analysis in east's alternative 
In conclusion, the alternative that generates the greatest benefit in terms of savings in average travel times to a greater percentage of the population is the northern alternative, followed by the alternative West- 2 which generates considerable savings especially in the part of Villamaría with lower accessibility, "La Pradera" neighborhood. For this reason, in the pre-feasibility phase, two alternatives should be considered to make more cost-benefit studies and thus determine which of these will be considered for its construction. These subsequent studies could be complemented with supply modeling, taking into account the update of the origin-destination matrix made for the MMP 2017.

\section{Acknowledgments}

The researchers would like to thank the hotbed of research in sustainable mobility of the National University of Colombia, particularly the student of Civil Engineering Nicolas Castro for his collaboration in the creation of the alternatives and their inclusion in the graph of the road network of the study area.

\section{References}

Cardona, S., Escobar, D., \& Moncada, C. (2017). Evolución del número de pasajeros movilizados en los Sistemas estratégicos de transporte público en Colombia. Análisis cuantitativo. Revista Espacios, 38(53).

Congress of the Republic from Colombia - Congreso de la República de Colombia. (2006). Ley 1083 de 2006.

Congress of the Republic from Colombia - Congreso de La República de Colombia. (1997). Ley 388 de 1997- Ley del Desarrollo Teritorial. Diario Oficial.

Dalvi, M. Q., \& Martin, K. M. (1976). The measurement of accessibility: Some preliminary results. Transportation, 5(1), 17-42. https://doi.org/10.1007/BF00165245

Deo, N. (1974). Graph theory with applications to engineering and computer science.

Departamento Administrativo Nacional de Estadística - DANE (2010). Proyecciones de población total por sexo y grupos de edad de 0 hasta 80 y más años (2005-2020). Retrieved from http://www.dane.gov.co/index.php/estadisticas-por-tema/demografia-y-poblacion/proyecciones-depoblacion

Departamento Administrativo Nacional de Estadística - DANE (2010). Proyecciones de población total por sexo y grupos de edad de 0 hasta 80 y más años (2005-2020). Retrieved from http://www.dane.gov.co/index.php/estadisticas-por-tema/demografia-y-poblacion/proyecciones-depoblacion

Derrible, S., \& Kennedy, C. (2009). Network Analysis of World Subway Systems Using Updated Graph Theory. Transportation Research Record: Journal of the Transportation Research Board, 2112, 17-25. https://doi.org/10.3141/2112-03

Díaz Viera, M. A. (2002). Geoestadística Aplicada. Universidad Autonoma de México. Ciudad de México.

Dijkstra, E. W. (1959). A note on two problems in connexion with graphs. Numerical Mathematics, 1(1), 269-271.

Duarte, S., Becerra, D., \& Niño, L. (2008). Un modelo de asignación de recursos a rutas en el sistema de transporte masivo. Avances En Sistemas E Informática, 5(1), 163-171.

Escobar, D. A., \& García, F. J. (2012). ANÁLISIS DE PRIORIZACIÓN DE PROYECTOS VIALES Caso Manizales (Colombia) (First Edition).

Escobar, D. A., Cardona, S., \& Moncada, C. A. (2018a). Global Mean Accessibility in Metropolitan Areas . Case Study: Chinchiná , Colombia. Indian Journal of Science and Technology, 11(21). https://doi.org/10.17485/ijst/2018/v11i21/123113

Escobar, D. A., Cardona, S., \& Moncada, C. A. (2018b). Urban Territorial Accessibility Through Road Infrastructure Works and Betterment Levy Area. Research Journal of Applied Sciences, 13(7), 431-438. https://doi.org/10.3923/rjasci.2018.431.438

Escobar, D. A., Montoya, J. A., \& Moncada, C. A. (2018). Accessibility Analysis towards Urban Ecoparks as a Measure of Integral Environmental Planning - Case Study : Manizales, Colombia. Indian Journal of Science and Technology, 11(21). http://doi.org/10.17485/ijst/2018/v11i21/122476

Geurs, K. T., \& Ritsema van Eck, J. (2001). Accessibility measures: review and applications. Evaluation of accessibility impacts of land-use transportation scenarios, and related social and economic impact. RIVM Report, 787, 1-265. Retrieved from https://rivm.openrepository.com/rivm/handle/10029/9487

Geurs, K. T., \& van Wee, B. (2004). Accessibility evaluation of land-use and transport strategies: Review and 
research directions. Journal of Transport Geography, 12(2), 127-140. http://doi.org/10.1016/j.jtrangeo.2003.10.005

Geurs, K. T., De Montis, A., \& Reggiani, A. (2015). Recent advances and applications in accessibility modelling. $\begin{array}{lllll}\text { Computers, } \quad \text { Environment } & \text { 8nd }\end{array}$ http://doi.org/10.1016/j.compenvurbsys.2014.09.003

Hansen, W. G. (1959). How Accessibility Shapes Land Use. Journal of the American Institute of Planners, 25(2), 73-76. https://doi.org/10.1080/01944365908978307

Ingram, D. R. (1971). The Concept of Accessibility: A search for an operational form. Regional Studies, 5(2), 101 107. https://doi.org/10.1080/09595237100185131

Koenig, J. G. (1980). Indicators of urban accessibility: Theory and application. Transportation, 9(2), 145-172. https://doi.org/10.1007/BF00167128

Lindner, A., Pitombo, C. S., Rocha, S. S., \& Quintanilha, J. A. (2016). Estimation of transit trip production using Factorial Kriging with External Drift: an aggregated data case study. Geo-Spatial Information Science, 19(4), 245-254. https://doi.org/10.1080/10095020.2016.1260811

Manizales Como Vamos. (2017). Informe de Calidad de Vida 2016.

Marvin, S., \& Guy, S. (1999). POLICY FORUM: Towards a new logic of transport planning ? Town Planning Review, 70(2), 139-158. https://doi.org/10.3828/tpr.70.2.e7856q7168802614

Mayoralty of Manizales. (2017a). Plan de Ordenamiento Territorial del Municipio de Manizales 2015-2027. Componente General. Manizales: Alcaldía de Manizales. Retrieved from http://www.manizales.gov.co/Contenido/Alcaldia/4448/plan-de-ordenamiento-territorial-2017-2031

Mayoralty of Manizales. (2017b). Plan Maestro de Movilidad: Formulación del plan maestro de Movilidad de Manizales. Manizales.

Mayoralty of Manizales. (2017c). Plan Maestro de Movilidad de Manizales: Línea base y diagnóstico de la situación actual de la movilidad de Manizales. Manizales.

Miller, H. J. H. J. (1999). Measuring Space-Time Accessibility Benefits within Transportation Networks : Basic Theory and Computational Procedures. Geographical Analysis, 31(1), 1-26.

Moncada, C. A., Cardona, S., \& Escobar, D. A. (2018). Saving Travel Time as an Urban Planning Instrument . Case Study: Manizales, Colombia. Modern Applied Science, 12(6), 44-57. https://doi.org/10.5539/mas.v12n6p44

Montoya, J. A., \& Escobar, D. A. (2017). Propuesta de ubicación de nuevos centros comerciales , aplicación de un análisis de accesibilidad territorial urbana. Revista Espacios, 38(51).

Morris, J. M., Dumble, P. L., \& Wigan, M. R. (1979). Accessibility indicators for transport planning. Transportation Research Part A: General, 13(2), 91-109. https://doi.org/10.1016/0191-2607(79)90012-8

Muñoz-Espinosa, A. F. (2016). Análisis de accesibilidad territorial a nivel regional y el impacto de las concesiones 4 G Proyecto Autopistas para la Prosperidad Pacifico 1, 2 y 3.

Oliver, M. A., \& Webster, R. (1990). International journal of geographical information systems Kriging : a method of interpolation for geographical information systems. International Journal of Geographical Information Systems, 4(3), 313-332. https://doi.org/10.1080/02693799008941549

Ortúzar, J. D., \& Willumsen, L. G. (1994). Modelling Transport. Modelling Transport (4th Ed.). John Wiley \& Sons, Ltd. https://doi.org/10.1002/9781119993308

Perilla, D. J., Escobar, D. A., \& Cardona, S. (2018). New Transportation Infrastructure Impact in Terms of Global Average Access - Intersection " La Carola " Manizales (Colombia ) Case Study. Contemporary Engineering Sciences, 11(5), 215-227. http://doi.org/https://doi.org/10.12988/ces.2018.812

Pirie, G. H. (1979). Measuring Accessibility: A Review and Proposal. Environment and Planning A, 11(3), 299312. https://doi.org/10.1068/a110299

Sanders, P., \& Schultes, D. (2007). Engineering fast route planning algorithms. Proceedings of the 6th International Conference on Experimental Algorithms, 23-36. https://doi.org/10.1007/978-3-540-72845-0

Te Brömmelstroet, M., \& Bertolini, L. (2011). The role of transport-related models in urban planning practice. Transport Reviews, 31(2), 139-143. https://doi.org/10.1080/01441647.2010.541295 
van Wee, B. (2016). Accessible accessibility research challenges. Journal of Transport Geography, 51, 9-16. https://doi.org/10.1016/j.jtrangeo.2015.10.018

Weibull, J. W. (1976). An axiomatic approach to tee measuwm1ent of. Regional Science and Urban Economics, 6(4), 357-379. http://doi.org/10.1016/0166-0462(76)90031-4

Zhang, D., \& Wang, X. C. (2014). Transit ridership estimation with network Kriging: A case study of Second Avenue Subway, NYC. Journal of Transport Geography, 41, 107-115. https://doi.org/10.1016/j.jtrangeo.2014.08.021

\section{Copyrights}

Copyright for this article is retained by the author(s), with first publication rights granted to the journal.

This is an open-access article distributed under the terms and conditions of the Creative Commons Attribution license (http://creativecommons.org/licenses/by/4.0/). 